\title{
Correlation between Physico-Chemical Properties and Engineering Properties of Soil Samples from Pinousuk Gravel Deposit of Mesilou, Kundasang, Sabah
}

\author{
Hennie Fitria Wulandary Soehady Erfen*, Baba Musta, Darmesah Gabda and Junaidi Asis \\ Faculty of Science and Natural Resources, Universiti Malaysia Sabah, Jalan UMS, 88400 Kota \\ Kinabalu, Sabah
}

\begin{abstract}
Ten soil samples from Pinousuk Gravel unit were collected for physico-chemical and engineering properties investigation. Pinousuk Gravel originated from different parent rocks namely ultrabasic, granodiorite, sandstones, and shale from sedimentary rock formations. The correlation between physicochemical and engineering properties were analyzed using Spearman's correlation. The result of analysis shows strong relationship (range from .59 to .83) between moisture content (V1) and clay percentage $\left(\mathrm{V}_{7}\right)$ on the compressive strength (V13) of soil. This is due to the increasing of the liquid limit (V9) and soil plasticity (V11) which decrease the strength of soil.
\end{abstract}

Keywords: Physico-chemical properties, engineering properties, Pinousuk Gravel, soils, correlation matrix

\section{INTRODUCTION}

The study area is located at Mesilou, Kundasang, Sabah where Pinousuk Gravel is widely distributed on the area. Pinousuk Gravel is an unconsolidated, loose materials formed around 34000 to 40000 years back (Jacobson, 1970) due to the glacial deposition from Mount Kinabalu during Pleistocene age (Marilah \& Ibrahim, 2000). Pinousuk Gravel is also known as tilloid deposit which can be observed by its blocky sizes and angular shaped rocks. Jacobson (1970) and Koopmans and Stauffer (1967) has characterized Pinousuk Gravel into two different units ie Upper Unit and Lower Unit based on its size, roundness, and sphericity of rock units. The distinct differences were Lower Unit was characterized by the angular deposited blocks, less weathered, and dominated by sandstones and ultrabasic rocks. While Upper Unit consists of rounded shaped granodiorite that deposited from mud flow transportation process. This is supported by Hall et. al., (2008) where Pinousuk Gravel is consisted of materials such as blocks embedded in mud and sand matrixes from Mount Kinabalu and its surroundings. The effect of glacial meltdown has encouraged the mud flow events which enabled to transport the granodiorite blocks, ultrabasic and sedimentary rocks before deposited on Pinousuk Plateu (Sahibin et. al., 1989).

The study area consists of unconsolidated, weak with bad sorting materials which increased the risk of landslide occurrences (Liau, 1996). The mixture of various types of parent rocks in Pinousuk Gravel will produce different rate of soil strength based on its mineralogy and soil texture. Therefore, the purpose of this research is to study the physico-chemical properties and engineering properties of the soil samples from Pinousuk Gravel and to establish the correlation among these parameters using Spearman's correlation coefficient. 

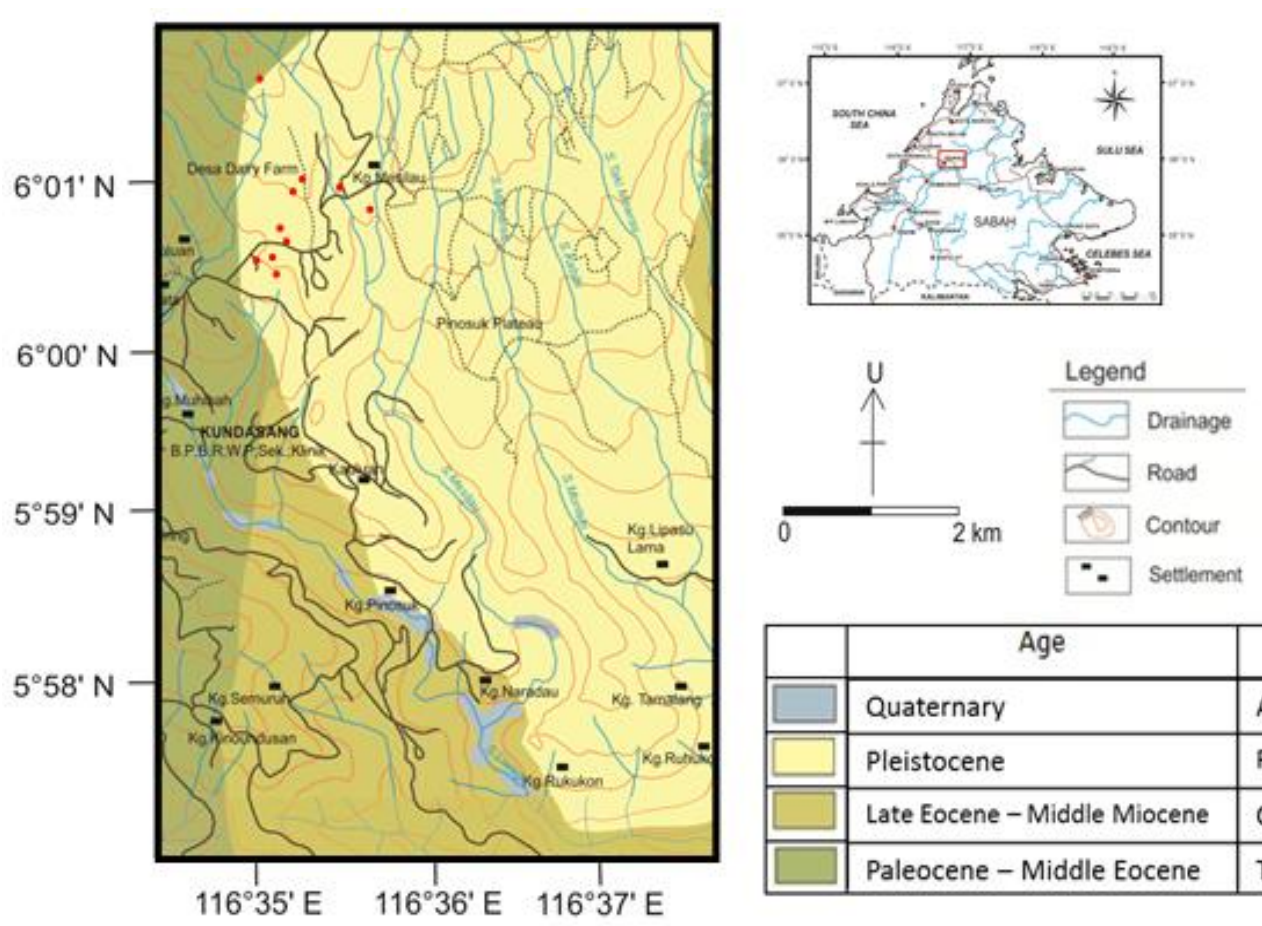

\begin{tabular}{|l|l|l|}
\hline & \multicolumn{1}{|c|}{ Age } & \multicolumn{1}{c|}{ Formation } \\
\hline$\square$ & Quaternary & Alluvium \\
\hline$\square$ & Pleistocene & Pinosouk Gravel \\
\hline$\square$ & Late Eocene - Middle Miocene & Crocker \\
\hline$\square$ & Paleocene - Middle Eocene & Trusmadi \\
\hline
\end{tabular}

Figure 1. Soil sampling locations on the geological map of the study area

\section{MATERIALS AND METHODS}

Ten (10) soil samples were collected from different locations of Pinousuk Gravel Plateu in the study area (Fig. 1) namely as S1 - S10 (Fig. 2). Samples were collected from different types of soil lithology and texture, where $\mathrm{S} 1$ is a dominated ultrabasic soil among 1 meter diameter of rocks, while $\mathrm{S} 2$ and $\mathrm{S}_{3}$ are consist of mixture of fragments-matrix originated of ultrabasic rocks with size of fragments up to more than 1 meter. $\mathrm{S}_{4}$ and $\mathrm{S}_{5}$ are dominated by smaller size of fragments with less than $30 \mathrm{~cm}$ and lithology mostly from ultrabasic rocks as well, while $\mathrm{S} 6, \mathrm{~S} 7$ and $\mathrm{S} 8$ are soils from granodiorite where slope S8 is consists of granodiorite boulders with size more than 2 meters diameter. Both S9 and S10 were collected from landslide area and consists of mixture of ultrabasic and granodiorite with fragments size from few centimeters to less than 1-meter blocks.

All laboratory analysis was based on British Standard 1377 (1990) except the unconfined compression test which followed the ASTM standards (2000). This contributes to 14 different variables to be measured their correlations. The parameters for physico-chemical analysis include moisture content, organic content, $\mathrm{pH}$ value, particle size distribution, soil specific gravity and Atterberg Limit. Engineering properties consist of unconfined compression test for strength analysis and permeability test.
For statistics analysis, Spearman's correlation coefficient was used to measure relationship between two variables where correlation matrix is produced to see which variables have the strong correlation (Ahmad Shukri et. al., 2008). The value is between -1 and 1 , where 1 indicates a perfect positive relationship while -1 indicates a perfect negative relationship. A result of zero indicates no relationship at all. 

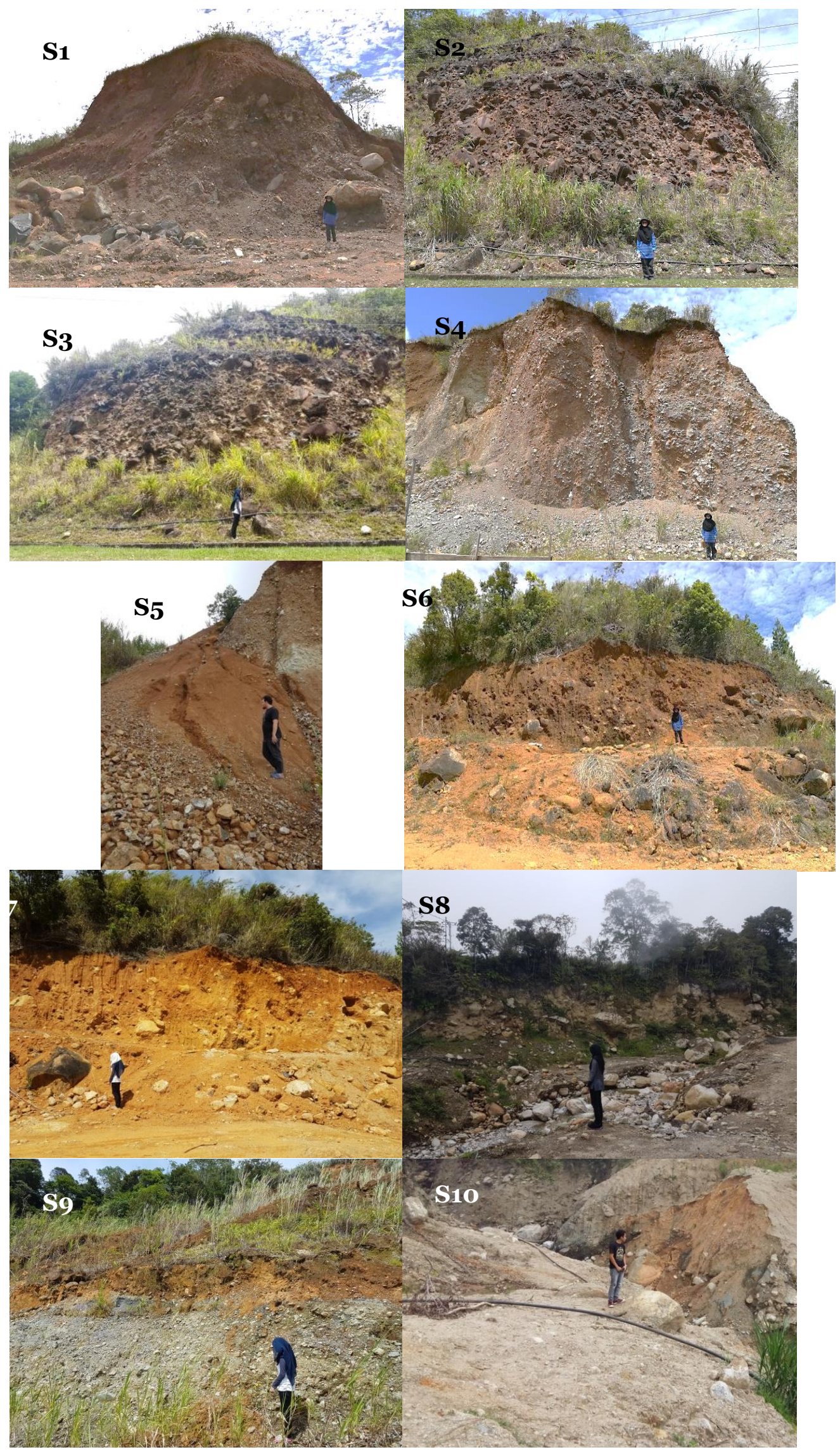

Figure 2. Selected soil slopes of the study area consist of different types of rocks and size of fragments 


\section{RESULTS AND DISCUSSIONS}

\section{A. Laboratory Analysis}

Table 1 shows the result of physico-chemical and engineering properties for 10 soil samples from Pinousuk Gravel unit. Based on the result, it is found that the moisture content was at the range of $22.08 \%$ to $81.15 \%$, organic content between $0.91 \%$ and $6.63 \%, \mathrm{pH}$ was 4.53 to 7.98 and specific gravity at the range of 2.43 to 2.64. S1 shows the highest content of moisture and organic and the lowest for $\mathrm{pH}$ and specific gravity. This is related to the formation of organic compounds and high content of iron oxide which led to the acidity of soil. Low value of specific gravity is generally influenced by the existence of organic matter (Bowles, 1979; Bujang et. al., 2009).

The triangular chart classification indicates that the samples are best classify as sandy \& silty clay, sandy silt, clayey sand, sandy \& silty clay, clay, sandy clay with silt, slightly clayey sand, clayey sand and clayey \& sandy silt (Fig. 3). Based on plasticity chart classification, the soil plasticity can be classified from low (S8), moderate (S9, S10), high (S1, $\left.\mathrm{S}_{3}, \mathrm{~S}_{5}, \mathrm{~S} 6, \mathrm{~S} 7\right)$ to very high $\left(\mathrm{S}_{2}, \mathrm{~S}_{4}\right)$ with non-active to normal clay activities (Skempton, 1953) (Fig. 4).

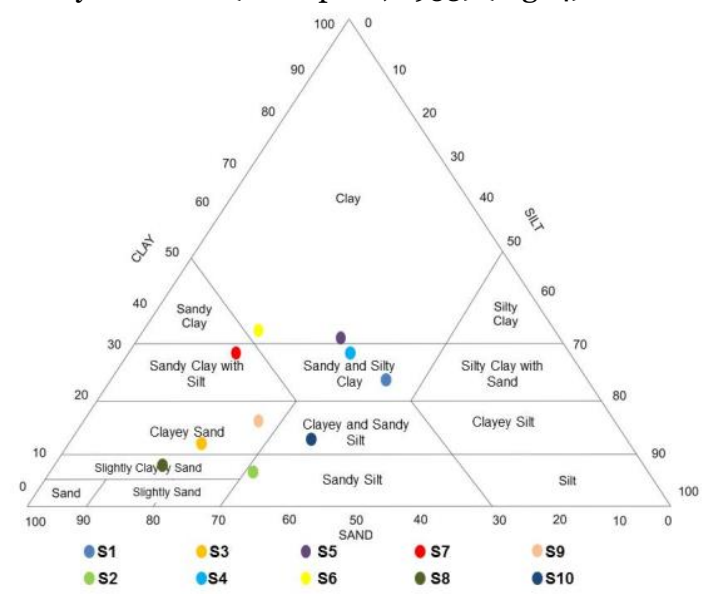

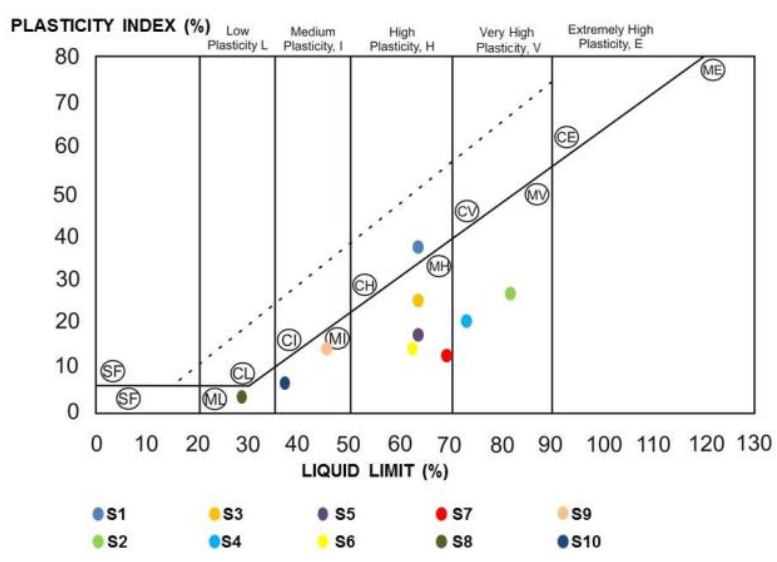

Figure 4. Plasticity chart indicates the plasticity of soil samples

For compressive strength test, all samples show range of value from $11.24-77.50 \mathrm{kPa}$ where it is classified as very soft to medium consistency according to Terzaghi et. al., (1996). Braja (2002) suggested that soil mineralogy, organic content, moisture content and pore ratio can contribute to affect the compression strength of soil, besides the appearance of clay minerals (Olson, 1974). Higher percentage of clay increases the plasticity rate of soil which enables it to expand and entrap more moisture to lower down the friction angle and cohesion among soil particles (Zydroń \& Dąbrowska, 2012; Dafalla, 2013). All samples show range of permeability degree from very low to impermeable (Terzaghi \& Peck, 1948) due to variety of particle sizes which provided different interconnected pores.

Figure 3. Triangular chart shows the soil texture classification

Table 1. Physico-chemical and engineering properties variables (namely V1 - V14) analyzed on 10 soil samples from Pinousuk Gravel

\begin{tabular}{|l|c|c|c|c|c|c|c|c|c|c|}
\hline \multicolumn{1}{|c|}{ Samples } & S1 & S2 & S3 & S4 & S5 & S6 & S7 & S8 & S9 & S10 \\
\hline $\begin{array}{l}\text { Moisture Content } \\
(\mathrm{V} 1)(\omega, \%)\end{array}$ & 81.15 & 42.93 & 22.08 & 77.51 & 63.43 & 43.51 & 48.92 & 23.09 & 36.00 & 22.70 \\
\hline Organic Content & 6.63 & 1.53 & 1.22 & 5.30 & 4.8 & 2.84 & 3.06 & 0.91 & 7.40 & 1.07 \\
\hline
\end{tabular}


ASM Science Journal, Volume 13, 2020

\begin{tabular}{|c|c|c|c|c|c|c|c|c|c|c|}
\hline (V2) (BOT, \%) & & & & & & & & & & \\
\hline $\mathrm{pH}\left(\mathrm{V}_{3}\right)$ & 4.53 & 7.98 & 7.47 & 6.37 & 6.58 & 5.43 & 5.23 & 4.62 & 6.13 & 6.55 \\
\hline $\begin{array}{l}\text { Specific Gravity } \\
(\mathrm{V} 4)\end{array}$ & 2.43 & 2.56 & 2.49 & 2.48 & 2.50 & 2.46 & 2.45 & 2.64 & 2.51 & 2.50 \\
\hline \% Sand (V5) & 28.91 & 60.34 & 68.74 & $34 \cdot 39$ & 36.34 & 48.56 & 52.47 & 76.18 & $55 \cdot 5^{2}$ & 52.61 \\
\hline \% Silt (V6) & 44.99 & 7.83 & 20.17 & 36.45 & 32.73 & 21.09 & 19.36 & 18.21 & 27.68 & 35.16 \\
\hline \% Clay (V7) & 26.10 & 31.83 & 11.09 & 29.16 & 30.93 & 30.35 & 28.17 & 5.60 & 16.80 & 12.23 \\
\hline $\begin{array}{l}\text { Plastic Limit (V8) } \\
\text { (PL, \%) }\end{array}$ & $33 \cdot 5^{2}$ & 56.78 & 44.02 & $55 \cdot 71$ & 50.04 & 50.89 & 57.81 & 26.72 & 33.42 & 32.13 \\
\hline $\begin{array}{l}\text { Liquid Limit (V9) } \\
\text { (LL, \%) }\end{array}$ & 64.00 & 82.00 & 65.00 & 71.90 & 64.71 & 64.20 & 69.45 & 30.00 & 47.00 & 37.80 \\
\hline $\begin{array}{l}\text { Linear Shrinkage } \\
\text { (V10) (LS, \%) }\end{array}$ & 10.71 & 13.57 & 19.86 & 12.86 & 11.35 & 5.71 & $7 \cdot 36$ & 2.86 & 4.29 & 5.71 \\
\hline $\begin{array}{l}\text { Plasticity Index } \\
\text { (V11) (PI, \%) }\end{array}$ & 30.48 & 25.22 & 20.98 & 16.19 & 14.67 & $13 \cdot 31$ & 11.64 & 3.28 & 13.58 & 5.67 \\
\hline $\begin{array}{l}\text { Clay Activity (V12) } \\
\text { (A) }\end{array}$ & 1.65 & 0.79 & 1.89 & 0.56 & 0.47 & 0.44 & 0.41 & 0.59 & 0.80 & 0.46 \\
\hline $\begin{array}{l}\text { Compression } \\
\text { strength }\left(\mathrm{V}_{13}\right)(\tau \text {, } \\
\mathrm{kPa})\end{array}$ & 11.24 & $25 \cdot 7$ & 26.15 & 26.86 & 19.76 & 37.88 & 38.94 & $77 \cdot 50$ & 13.66 & 56.08 \\
\hline $\begin{array}{l}\text { Permeability } \\
(\mathrm{V} 14)(\mathrm{k}, \mathrm{m} / \mathrm{s})\end{array}$ & $\begin{array}{c}3.68 \mathrm{x} \\
10^{-8}\end{array}$ & $\begin{array}{c}1.13 \mathrm{x} \\
10^{-8}\end{array}$ & $\begin{array}{c}1.60 \mathrm{x} \\
10^{-9}\end{array}$ & $\begin{array}{c}2.55 \mathrm{x} \\
10^{-8}\end{array}$ & $\begin{array}{c}1.21 \mathrm{x} \\
10^{-8}\end{array}$ & $\begin{array}{c}4.05 \mathrm{x} \\
10^{-9}\end{array}$ & $\begin{array}{c}8.76 x \\
10^{-9}\end{array}$ & $\begin{array}{c}4.04 \mathrm{x} \\
10^{-8}\end{array}$ & $\begin{array}{c}1.63 x \\
10^{-8}\end{array}$ & $\begin{array}{c}5.68 \mathrm{x} \\
10^{-9}\end{array}$ \\
\hline
\end{tabular}

\section{B. $\quad$ Statistics Analysis}

Based on Table 2, the strongest positive relationship is observed between the percentage of clay $\left(\mathrm{V}_{7}\right)$ versus plastic limit (V8) and percentage of clay (V7) versus liquid limit (V9) with the value of .80 and .83 respectively. This shows that clay particles and clay minerals in soils be able to increase the plastic limit and liquid limit. Large surface area of clay particles and minerals enable it to absorb more moisture thus increase its plasticity. Whereas, it was also found that moisture content (V1) in soil is reducing with the increasing of sand percentage $\left(\mathrm{V}_{5}\right)$ due to the occurrence of seepage among the pores between sand particles. The correlation value shows negative decrease of a fixed proportion in the other.
Other pairs of variables show strong positive relationship are (V1)/ (V7) (.73), (V9)/ (V11) (.72) V10/V11 (.67) and V9/V10 (.67). While these pair of variables show strong negative relationships: $(\mathrm{V} 11) /\left(\mathrm{V}_{13}\right)(-.79)$ and (V9)/(V13) (-.72). This shows that an addition of moisture content $\left(\mathrm{V}_{1}\right)$ and the percentage of clay $\left(\mathrm{V}_{7}\right)$ increase the liquid limit (V9) and plasticity (V11) in soil which decrease the strength of soil (V13) as expected (Blahova et. al., 2013). The moisture within pores prepares a failure axis among particles to collide and acted as lubricants for easier fails.

Other pairs of variables are considered as weak to medium relationship with value of correlation from -.50 to .50 which means for every increase or decrease, it is not affect much of variation of a fixed proportion in the other. 
Table 2. Correlation matrix of variables for physico-chemical and engineering properties analysis

\begin{tabular}{|c|c|c|c|c|c|c|c|c|c|c|c|c|c|c|}
\hline & V1 & V2 & V3 & $\mathrm{V}_{4}$ & $V_{5}$ & V6 & $v_{7}$ & V8 & V9 & V10 & V11 & V12 & V13 & V14 \\
\hline V1 & 1.00 & & & & & & & & & & & & & \\
\hline V2 & 0.69 & 1.00 & & & & & & & & & & & & \\
\hline$V_{3}$ & -0.24 & -0.28 & 1.00 & & & & & & & & & & & \\
\hline$V_{4}$ & -0.54 & -0.48 & 0.11 & 1.00 & & & & & & & & & & \\
\hline V5 & -0.90 & -0.70 & 0.19 & 0.71 & 1.00 & & & & & & & & & \\
\hline V6 & 0.58 & 0.61 & -0.36 & -0.52 & -0.76 & 1.00 & & & & & & & & \\
\hline $\mathbf{V}_{7}$ & 0.73 & 0.38 & 0.12 & -0.51 & -0.68 & 0.05 & 1.00 & & & & & & & \\
\hline V8 & 0.38 & -0.03 & 0.41 & -0.35 & -0.27 & -0.33 & 0.80 & 1.00 & & & & & & \\
\hline V9 & 0.55 & 0.17 & 0.42 & -0.48 & -0.41 & -0.17 & $\mathbf{0 . 8 3}$ & 0.87 & 1.00 & & & & & \\
\hline V10 & 0.21 & -0.09 & 0.64 & -0.26 & -0.11 & -0.04 & 0.22 & 0.45 & 0.67 & 1.00 & & & & \\
\hline V11 & 0.55 & 0.37 & 0.24 & -0.44 & -0.42 & 0.14 & 0.49 & 0.29 & 0.72 & 0.67 & 1.00 & & & \\
\hline V12 & 0.03 & 0.10 & 0.12 & -0.22 & 0.05 & 0.15 & -0.25 & -0.25 & 0.17 & 0.63 & 0.68 & 1.00 & & \\
\hline V13 & -0.59 & -0.72 & -0.29 & 0.62 & 0.60 & -0.31 & -0.68 & -0.72 & -0.83 & -0.51 & -0.79 & -0.43 & 1.00 & \\
\hline V14 & 0.38 & 0.32 & -0.62 & 0.33 & -0.13 & 0.34 & -0.18 & -0.47 & -0.31 & -0.29 & 0.05 & 0.10 & 0.17 & 1.00 \\
\hline
\end{tabular}

\section{SUMMARY}

Soil of Pinousuk Gravel unit is known for its weak, loose materials which commonly contributed to landslides. From the laboratory and statistics analysis, it can be concluded that most of the physical properties shows significant correlation with the soil strength.

In summary, this study shows that the compression strength (V13) of soil samples is highly influenced by the percentage of clay particle $\left(\mathrm{V}_{7}\right)$, high plasticity index (V8/V9) and moisture content (V1) due to capability of moisture absorption which resulted to higher expansion and failure.

\section{ACKNOWLEDGMENT}

This study was supported by Universiti Malaysia Sabah under Research Grant Scheme code SBKo276-STWN2016. Special thanks to Mizan Syazwani, Sylvia Hunyang and Asvirja Grace for soil collection and lab testing. 


\section{REFERENCES}

Jacobson, G. 1970, Gunung Kinabalu Area, Sabah, Malaysia. Geological Survey Report, Report 8, 118.

Marilah Sarman \& Ibrahim Komoo. 2000, KundasangRanau: Dataran Warisan Ais Gunung. Geological Society of Malaysia, Annual Geological Conference.

Koopmans, B.N. \& Stauffer, P.H. 1967, Glacial Phenomenon on Mount Kinabalu, Sabah. Borneo Region Malaysia Geological Survey Bulletin, 8, 25-35

Hall, R., Cottam, M., Suggate, S., Tongkul, F, Sperber, S \& Batt, G. 2008, The Geology of Mount Kinabalu. Sabah Park Publication, 13.

Sahibin Abd. Shariff Abd. Kadir S. Omang, Sahat Sadikun, Abd. Nasir Abd. Latif \& Shafiee Bakar. 1989, Kerikil Pinosuk - Litologi dan Kawasan Pengendapan di Dataran Pinosuk. Universiti Kebangsaan Malaysia.

Liau, A. 1996, Major Landslides at Kampung Pinousuk, Kundasang, Ranau. Jabatan Penyiasatan Kaji Bumi, Kota Kinabalu.

British Standard 1377. 1990, Method of Test Soil for Civil Engineering Purposes. British Standard Institution, London.

American Society for Testing Material. 2000, Unconfined Compressive Strength of Cohesive Soil (ASTM D-2166), Annual Book of ASTM Standard, Philadelphia.

Ahmad Shukri Yahaya, Amran Ahmed, Darmesah Gabda \& Chin Su Na. 2008, Problems \& Solutions in Statistics for Engineers \& Scientists. Pearson Publisher.

Bowles, J.E. 1979, Engineering Properties of Soil and Theie Measurement. $4^{\text {th }}$ Ed, Pearson Edu.

Bujang, B.K. Huat, Afshin Asadi \& Sina Kazemian. 2009, Experimental Investigation on Geomechanical Properties of Tropical Organic Soils and Peat. American Journal of Engineering and Applied Sciences, 2 (1), 184188.

Skempton, A.W. 1953, The Colloidal Activity of Clays. Proceedings of $3^{\text {rd }}$ International Conference on Soil Mechanics and Foundation Engineering, 1, 57-61.

Terzaghi, K., Peck, R.B. \& Mesri, G. 1996, Soil Mechanics in Engineering Practice, John Wiley \& Sons.

Braja, M.D. 2002, Soil Mechanics Laboratory Manual. Oxford University Press, New York.
Olson, R.E. 1974, Shearing Strength of Kaolinite, Illite and Montmorillonite. Journal of the Geotechnical Division, $100,1215^{-1299}$

Zydroń, T. \& Dąbrowska, J. 2012, The Influeve of Moisture Content on Shear Strength of Cohesive soils from the Landslide Area around Gorlice. Journal of Mining and Geoengineering. 36 (2), 309-317

Dafalla, M.A. 2013, Effects of Clay and Moisture Content on Direct Shear Tests for Clay-Sand Mixtures. Advances in Materials Science and Engineering, 4, 1-8.

Terzaghi, K. \& Peck, R.B. 1948, Soil Mechanics inEngineering Practice. John Wiley, New York.

Blahova, K., Sevelova, L. \& Pilarova, P. 2013, Influence of Water Content on the Shear Strength Parameters of Clayey Soil in relation to Stability Analysis of a Hillside in Brno Region. Acta Universitatis Agriculturae et Silviculturae Mendelianae Brunensis, 61(6), 1583-1588. 